\title{
Analysis of Energy Consumption Structure Optimization Based on Low- carbon Economic Paradigm
}

\author{
Wang Ning $^{*}, 1$, Jian Ming ${ }^{2}$ and Mingqiang $\mathrm{Lu}^{3}$ \\ ${ }^{1}$ Computer Science Department, Northeast Petroleum University at Qinhuangdao, Qinhuangdao, 066004, Hebei, China \\ ${ }^{2}$ School of Statistics, Renmin University of China, Beijing, 100872, China \\ ${ }^{3}$ Department of Tourism Management, Northeast Petroleum University at Qinhuangdao, Qinhuangdao, 066004, Hebei, \\ China
}

\begin{abstract}
With the rapid development of our economy, the production is largely expanded and people's living standard is greatly improved. However, energy consumption also brought us with many problems, which have been of wide concern by the whole world. To develop a low-carbon economy is an inevitable trend of solving the energy consumption problem for energy development. Moreover, the current energy utilization is not effective and there exists a high waste of natural resources, which increased the ecological pressure. Under the direction of low-carbon economy, the optimization of energy consumption structure can improve the energy utilization and protect the ecological environment. Based on lowcarbon economic paradigm, this paper uses AHP to calculate the energy structure optimization level to standardize the energy structure optimization and provide a reliable method.
\end{abstract}

Keywords: Energy consumption, Low-carbon economic paradigm, Structure optimization.

\section{INTRODUCTION}

Along with the promotion of globalization and development of economy, more and more problems emerged especially the relationship between economy, energy and the environment [1-4]. Regardless of the development, the energy consumption was severe, which lead to the phenomenon of energy crunch and the destruction of the ecological environment [5-7]. Hence, the energy and environment issues have been of great concern by the people. Low-carbon economy has provided a new way of energy development [8-10], which is also a development trend of the future. As in our country, there are many problems in the energy consumption structure. So we need to optimize our energy consumption structure on the basis of low-carbon economy to improve energy utilization and solve energy consumption problems. This paper will establish an energy optimization level evaluation system to quantify the optimization energy structure and lay a basis for the rationalization of energy structure.

\section{MAIN CONNOTATION OF LOW-CARBON ECO- NOMY AND ENERGY STRUCTURE}

\subsection{Connotation of Low-carbon Economy}

The formation basis of low-carbon economy includes low energy consumption, low pollution and low discharge of $\mathrm{CO}_{2}$. The implementation method is the application of

*Address correspondence to this author at the Computer Science Department, Northeast Petroleum University at Qinhuangdao, Qinhuangdao, 066004, Hebei, China; Tel: 13833523503; E-mail: 8546813@qq.com energy rate technology, emission reduction technology and renewable energy sources. While the market mechanism, government policy and strategy will guide the direction of low-carbon economy; the sign of low-carbon economy is that: the energy consumption was largely reduced, the discharge of noxious gas was apparently lowered, and an economic development mode of energy utilization, ecological environment and economic development coexisted was formed, which is also a new direction of any country. The essence of low-carbon economy is to realize the improvement of energy utilization rate and cleaning of energy structure, and to innovate in idea, strategy and energy technology. In the social development, low-carbon economy is a new mode. The low-carbon economy paradigm has changed the severe energy consumption and pollution social development mode. Nowadays low-carbon technology has been widely used in various fields. The technology will select the energy first before deciding the energy utilization method; secondly, it will improve technology and energy utilization method to reduce the discharge of noxious gas; finally, the technology will handle the noxious discharge. In brief, it means the development and utilization of the new energy source in order to realize the goal of energy conservation and emission reduction.

\subsection{Connotation of Energy Structure}

Energy structure refers to the proportion of total output and energy consumption between the primary and secondary energy sources. It mainly consists of supply structure and consumption structure. In the energy consumption structure, there are many types of energy sources such as natural gas, water, nuclear, wind power, oil and coal, etc. It shows that 
energy consumption structure means the consumption proportion of a specific energy source in the total energy consumption.

Energy planning is to estimate the energy demand according to the situation of the national economic and social development in a specific period. Therefore, all energy planning and energy consumption structure are based on the healthy and sustainable development of economy, energy and the environment. Energy utilization includes energy allocation and technology efficiency. Technology efficiency is to realize the maximum energy output and minimum energy input when deciding about energy input. Allocation efficiency refers that the output or input of all kinds of energy sources can be optimized under certain circumstances. Energy utilization rate mainly refers to the technology efficiency. Energy consumption structure optimization is to use market mechanism and government's macroeconomic regulation and control to allocate energy resources when energy sources and technology were restrained in order to make the consumption proportion in a most harmonious state to realize a maximum energy utilization.

The target of energy consumption structure is to realize a harmonious development of economy, energy source and environment in the procedure of energy consumption structure optimization under the restraint of low-carbon economy. So under the background of low-carbon economic paradigm, energy consumption structure optimization benefits not only the energy utilization but also the ecological effect. Table $\mathbf{1}$ shows our primary energy consumption structure proportion during 2005-2010:

According to Table 1, in our primary energy consumption structure, coal accounts for the largest proportion, while gas and hydropower have less occupation. In the period of 2005-2010, the change of the proportion of each energy source is not obvious. In 2010, coal accounted for $68.1 \%$ which is the lowest proportion of coal in this period. While hydropower and other resources accounted for $8.7 \%$ in this year, and natural gas also increased to some extent. All in all, the consumption of coal is the highest. But the use of coal is harmful to the environment, which indicates that the energy structure needs to be optimized.

\section{ESTABLISHMENT OF EVALUATION SYSTEM OF ENERGY STRUCTURE OPTIMIZATION BASED ON LOW-CARBON ECONOMIC PARADIGM}

Energy structure system is complicated and has a close relationship with our social life. Especially under the background of low-carbon economic paradigm with various impacts of related economic factors as economic growth, industrial structure, import and export trade, we should pay more attention to the energy conservation and emission reduction. As a result, it is difficult to evaluate the energy structure and the theory is also abstract. So qualification of energy structure with related computing method can judge whether the energy structure is rational, and an evaluation index system needs to be created before establishing the evaluation model.

To establish an evaluation index system, we should follow the principles as follows: first, we should stick to the systematic principle. We need to take the harmonious development of economy, energy and environment as our target with the theory of low-carbon economy. The system should contain the three aspects with distinct gradations of target, standard and index. The second principle is the operability principle. The purpose of the system is to evaluate the energy consumption structure and assure that the index data can be easily obtained from related documents or yearbooks and computed without any difficulties. The last principle is the effectiveness principle. That is to say, the energy consumption structure can be reflected by the evaluation system, and the selection of index should be typical and independent so that the rationalization degree of energy structure could be analyzed comprehensively.

\subsection{Evaluation Index System of Energy Structure Based on Low-Carbon Economic Paradigm}

The evaluation index system of energy structure is consisted of three subsystems. There are several indexes in each of the three gradations of economic, energy and ecological benefits. The details of the evaluation system are as follow:

As shown in Table 2, the evaluation system of energy structure based on low-carbon economic paradigm is consisted of social economic benefit, energy benefit and biological benefit. Social economic benefit contains 6 evaluating indexes including GDP growth rate, employment rate, imports and exports, industrial structure, total population, urbanization; energy benefit includes 5 evaluating indexes as energy safety, efficiency, price, supply and demand situation as well as renewable energy planning; ecological benefit includes 4 evaluating indexes as $\mathrm{CO}_{2}$ emission intensity, $\mathrm{SO}_{2}$ emission, dust emission and pollution control cost.

Table 1. Primary energy consumption structure (\%).

\begin{tabular}{|c|c|c|c|c|}
\hline Year & Coal (\%) & Petroleum (\%) & Gas (\%) & Hydropower (\%) \\
\hline \hline 2005 & 70.9 & 19.7 & 2.7 & 6.7 \\
\hline 2006 & 71.2 & 19.2 & 3.0 & 6.6 \\
\hline 2007 & 71.2 & 18.7 & 3.4 & 6.7 \\
\hline 2008 & 70.4 & 18.2 & 4.6 & 7.8 \\
\hline 2009 & 70.3 & 18.0 & 4.3 & 8.7 \\
\hline
\end{tabular}


Table 2. Evaluation index system of energy structure under low-carbon economic paradigm.

\begin{tabular}{|c|c|c|c|c|}
\hline Primary Index & Secondary Index & \multicolumn{3}{|c|}{ Third Class Index } \\
\hline Name & Name & Name (Unit) & Computation Instruction & Direction of Index \\
\hline \multirow{14}{*}{$\begin{array}{l}\text { Energy structure optimization } \\
\text { under low-carbon economic } \\
\text { paradigm }\end{array}$} & \multirow{6}{*}{$\begin{array}{l}\text { Social economic } \\
\text { benefit }\end{array}$} & GDP growth rate $(\%)$ & China Statistical Yearbook & $(+)$ \\
\hline & & Employment rate (\%) & $\begin{array}{l}\text { Employed population/Economically } \\
\text { active population }\end{array}$ & $(+)$ \\
\hline & & Industrial structure (\%) & The tertiary industry output/GDP & $(+)$ \\
\hline & & $\begin{array}{l}\text { Imports and exports (hundred } \\
\text { million yuan) }\end{array}$ & China Statistical Yearbook & $(+)$ \\
\hline & & Total population (hundred million) & China Statistical Yearbook & \\
\hline & & Urbanization (\%) & Urban population/Total population & $(+)$ \\
\hline & \multirow{4}{*}{ Energy benefit } & Energy price $\left(\right.$ tce $\left./ 10^{4}\right)$ & Price index of coal products & \\
\hline & & Energy safety (\%) & $\begin{array}{l}\text { Net exports of petroleum/petroleum } \\
\text { consumption }\end{array}$ & \\
\hline & & $\begin{array}{l}\text { Energy supply and demand } \\
\text { situation }\left(10^{4} \text { tce }\right)\end{array}$ & $\begin{array}{c}\text { Energy gap [energy supply-energy } \\
\text { demand] }\end{array}$ & $(-)$ \\
\hline & & Renewable energy planning (\%) & $\begin{array}{c}\text { Renewable energy } \\
\text { consumption/Total energy } \\
\text { consumption }\end{array}$ & $(+)$ \\
\hline & \multirow{4}{*}{ Ecological benefit } & $\begin{array}{l}\mathrm{CO}_{2} \text { emission intensity (tons of } \\
\text { carbon } / 10^{4} \text { yuan) }\end{array}$ & $\begin{array}{l}\text { (Primary energy consumption X } \\
\text { carbon emission coefficient)/GDP }\end{array}$ & $(+)$ \\
\hline & & $\mathrm{SO}_{2}$ emission (ten thousand tons) & China Statistical Yearbook & $(-)$ \\
\hline & & Dust emission (ten thousand tons) & China Statistical Yearbook & $(-)$ \\
\hline & & $\begin{array}{l}\text { Pollution treatment expense } \\
\text { (hundred million yuan) }\end{array}$ & China Statistical Yearbook & $(-)$ \\
\hline
\end{tabular}

SPSS18.0 software package will be used to evaluate each index and pick out the advisable indexes. In this investigation, we will use 5-scale scoring method to determine whether the evaluation index of energy structure is efficient or not. 1 point is inefficient, which means the index is unable to reflect the energy structure; 5 points is considered efficient, which means that the index can reflect the energy structure well. Then we will use the software to conduct the $\mathrm{T}$ value inspection of the index points. The $\mathrm{T}$ value is based on a value of 4.0. Only if the $T$ value is above 4.0 that can prove the evaluation index is able to reflect the rationalization degree of the energy structure and then we can choose this value in our experiments. The research is carried out with a questionnaire. Energy experts and scholars from 15 high schools were requested to complete the questionnaire. The distribution of the questionnaire is shown as Table 3.

According to Table 3, 206 sets of questionnaire were distributed and 146 of them were retrieved. Retrievable rate is $70.87 \%$. Among the 206 questionnaire, 139 sets are effective. The effective rate is $95.21 \%$. The result of the investigation is statistically significant $(\mathrm{P}<0.05)$.

\subsection{Evaluation Model}

\subsubsection{Rough Knowledge and Simple Theory}

This theory is a data tool proposed by mathematician $\mathrm{Z}$. Pawlak in 1982. It is mainly used in the treatment of fuzzy knowledge. Based on the same group ability, the theory use simple knowledge to delete the useless knowledge.

Definition 1: U stands for nonempty set. The equivalence relation on $\mathrm{U}$ is represented by $\mathrm{R} . \frac{U}{R}$ Shows all the equivalences of $R$. Knowledge base is represented by $K=(U$, $\mathrm{R})$. $\mathrm{U}$ refers to the discourse domain and $\mathrm{R}$ stands for the aggregation of equivalence relationship on $U$.

Definition 2: if $\mathrm{P} \subseteq \mathrm{R}$ and $\mathrm{P} \neq \phi$, then $\cap \mathrm{P}$ is an equivalence relationship and $\mathrm{P}$ is the intersection of the equivalence relationship. Relationship that is hard to distinguish on letter $\mathrm{P}$ can be represented by ind (P).

Definition 3: if $\mathrm{R}$ is an equivalence relationship, $\mathrm{r} \subseteq \mathrm{R}$, and ind $(R)=$ ind $(R-r)$, then $r$ is an unnecessary factor to $R$.

Table 3. Distribution of questionnaire.

\begin{tabular}{|c|c|c|c|c|}
\hline $\begin{array}{c}\text { Questionnaire Distributed } \\
\text { (Sets) }\end{array}$ & $\begin{array}{c}\text { Questionnaire Retrieved } \\
\text { (Sets) }\end{array}$ & $\begin{array}{c}\text { Retrievable Rate } \\
\text { (\%) }\end{array}$ & $\begin{array}{c}\text { Effective Questionnaire } \\
\text { (Sets) }\end{array}$ & $\begin{array}{c}\text { Effective Rate } \\
\text { (\%) }\end{array}$ \\
\hline \hline 206 & 146 & $70.87 \%$ & 139 & 95.21 \\
\hline
\end{tabular}


On the contrary, $r$ is a necessary factor to $R$. If $R$ in $r \subseteq R$ is a necessary factor, then $\mathrm{R}$ is independent. Otherwise, $\mathrm{R}$ is dependent.

Definition 4: if $\mathrm{Q} \subseteq \mathrm{P}, \mathrm{Q}$ is independent and ind $(\mathrm{Q})=$ ind $(\mathrm{P})$, then $\mathrm{Q}$ will be regarded as the brief of $\mathrm{P}$ and can be represented by red $(\mathrm{P})$.

Definition 5: in $U$, we assume $P$ is equivalently related to Q. $\operatorname{Pos}_{\mathrm{p}}(\mathrm{Q})$ shows that $\mathrm{Q}$ is the positive domain of P. As an object set, we absorb the U/R data existed in $U$ and group the equivalent factors of $\mathrm{Q}$ accurately.

Definition 6: assume the knowledge expression system to be $S=(U, R, V, f), P, Q \subseteq R$. The equation that can show the importance of $\mathrm{R}$ is as below:

$\mu_{R}=\frac{|| \operatorname{Pos}_{p}(Q)|-| \operatorname{Pos}_{p-|R|}(Q)||}{|U|}$

\subsubsection{Weight Analysis of Index}

The theory property of rough set is very important, which can be proved by the computation of each index. If the weight is above 0 , the data should be processed with normalized calculation in order to obtain the exact value of the index. The equation is as below:

$W_{i}^{R S T}=\mu i / \sum_{i} u i$

The weight can be set as AHP to determine the test index weight in $i$. And the test index weight of $i$ can be set by the rough theory of weight value. So that the test index of $i$ can be represented by $W i$. The equation is as below:

$W i=\theta w_{i}^{r e s}+(1-\theta) w_{i}^{A H P}$

where objective preference value coefficient and subjective preference value coefficient are included.

\subsubsection{Undetermined Measure Evaluation Theory}

$n$ evaluation targets can be set and we use $\mathrm{x}_{1}, \mathrm{x}_{2} \ldots \ldots \mathrm{x}_{\mathrm{n}}$, $\mathrm{X}=\left(\mathrm{x}_{1}, \mathrm{x}_{2} \ldots \ldots \mathrm{x}_{\mathrm{n}}\right)$ to represent the evaluation span, which can be generally called discourse domain. If $x_{i} \in X$, we assume the number of index as $m$. So the expressions can be $\mathrm{I}_{1}, \mathrm{I}_{2}$, $\mathrm{I}_{3} \ldots . . ., \mathrm{Im}$. Dimensional vector of $m$ is represented by $\mathrm{x}_{\mathrm{i}}$, and $\mathrm{xi}=\left(\mathrm{x}_{\mathrm{i} 1}, \mathrm{x}_{\mathrm{i} 2}, \ldots \mathrm{x}_{\mathrm{im}}\right) . \mathrm{x}_{\mathrm{ij}}$ is the evaluation value, representing the evaluation value of the targets. Each evaluation value has $k$ evaluation grades. The grades are represented by $\mathrm{c}_{1}, \mathrm{c}_{2}, \ldots$. $\mathrm{c}_{\mathrm{k}}$ and the evaluation vector is represented by $\mathrm{C}$.

\subsubsection{Single Index Measurement}

We assume $\mu=\mu\left(\mathrm{x}_{\mathrm{ij}} \in \mathrm{c}_{\mathrm{k}}\right)$ to demonstrate that the optimization level of the $\mathrm{k}$ evaluation grade is expressed by evaluation value. However, they need to satisfy the following conditions: (1) $0 \leq \mu\left(\mathrm{x}_{\mathrm{ij}} \in \mathrm{c}_{\mathrm{p}}\right) \leq 1$; (2) $\mu\left(\mathrm{x}_{\mathrm{ij}} \in C\right)=$ 1 ; (3) $\mu\left(x_{i j} \in \bigcup_{l=1}^{k} c_{1}\right)=\sum_{l=1}^{k} \mu\left(x_{i j} \in c_{1}\right)$. The mutual part of the three conditions is $\mu$, which we called the undetermined measurement. The evaluation formulas are as follows:

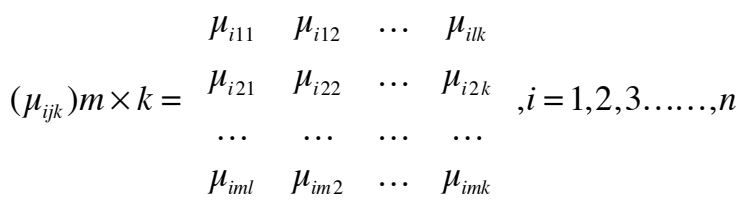

\subsubsection{Multi-Index Comprehensive Measurement}

In the computing procedure, the method computes and analyzes the data according to the most widely used reduction theory in the rough set, and explores the relationship and importance between the data. After the computation, related index of data index and weight index will be obtained. Through the transformation and computation of data relationship between the indexes, multiindex comprehensive measurement in the equation will be determined. The equation is shown as follows:

$\mu_{i k}=\sum_{j=1}^{m} w_{j} \mu_{i j k}, i=1,2, \ldots, n ; k=1,2 \ldots p$

\subsubsection{Recognition of Evaluation Grade}

For ordinal type evaluation in the computation, credible degree criteria method will be adopted. The equation of this method is as follows:

$k(x i)=\min \sum_{k=1}^{p} \mu_{i k}\left(c_{k}\right) \geq \lambda(1 \leq k \leq p)$

\section{CONCLUSION}

Under the background of low-carbon economic paradigm and based on related theory in and abroad, this paper created an evaluation index system that can reflect energy optimization and applied computing index as rough set theory for reduction. The system of energy structure optimization in low-carbon economic paradigm consists of three aspects: social economic benefit, energy benefit and ecological benefit. Among them, ecological benefit is the most critical aspect. The measurement can be carried out with 12 indexes. Among them, energy benefit, $\mathrm{CO}_{2}$ and renewable energy planning are the most important indexes, while other indexes as total population cannot reflect the degree of energy structure optimization. To realize energy consumption structure optimization in low-carbon economic paradigm, the key point is to conserve energy, reduce emission and improve the utilization rate of energy, and take environment protection as the basic idea to minimize the pollution and realize the harmonious development of economy, energy and environment.

\section{CONFLICT OF INTEREST}

The authors confirm that this article content has no conflict of interest.

\section{ACKNOWLEDGEMENTS}

This work is supported by Heilongjiang province education scientific planning project" Research and practice of college students' entrepreneurship education based on school-enterprise cooperation "(NO. ZJC1214002), Hebei 
province natural science fund project "research on port supply chain management key common problems (NO. G2015203378) and Qinhuangdao soft science research plan project" port two-way integration research on the structure analysis and optimization of the supply chain (NO. 201301B044), and Daqing city philosophy and social sciences planning research project in 2015 "research on promotion energy conservation and emissions reduction and speeding up the construction of green low-carbon transport environment in Daqing city."

\section{REFERENCES}

[1] Oliveira, C.; Antunes, C.H. A multiple objective model to deal with economy-energy-environment interactions. Euro. J. Operat. Res., 2004, 153(2), 370-385.

[2] Hawdon, D.; Pearson, P. Input-output simulations of energy, environment, economy interactions in the UK. Energy Eco., 1995, 17(1), 73-86.
[3] Kahouli-Brahmi, S. Technological learning in energyenvironment-economy modelling: A survey. Energy Policy, 2008, 36(1), 138-162.

[4] ZhiDong, L. An econometric study on China's economy, energy and environment to the year 2030. Energy Policy, 2003, 3l(11), $1137-1150$.

[5] LiU, Y.; Li, R.; Song, X. Analysis of Coupling Degrees of Urbanization and Ecological Environment in China. J. Nat. Resour., 2005, 1, 14

[6] Wang, Y.S.; Lou Z.P.; Sun C.C.; Sun S. Ecological environment changes in Daya Bay, China, from 1982 to 2004. Marine Pollut. Bull., 2008, 56(11), 1871-1879

[7] Wu, Q.; Shen Y.; Shi B. Relationship between frozen soil together with its water-heat process and ecological environment in the Tibetan Plateau. J. Glaciol. Geocryol., 2003, 25(3), 250-255.

[8] Bao, J.; Miao, Y.; Chen, F. Low Carbon Economy: Revolution in the Way of Human Economic Development. China Ind. Eco., 2008, 4, pp. 017.

[9] Liu, Z.L., Dai, Y., Dong, C.; Qi, Y. Low carbon city: concepts, international practice and implications for China. Urban Stud., 2009, 16(6), 1-7.

[10] Xin, Z.; Zhang, Y. Low carbon economy and low carbon city. Urban Stud., 2008, 4, 98-102.

This is an open access article licensed under the terms of the Creative Commons Attribution Non-Commercial License (http://creativecommons.org/licenses/ by-nc/4.0/) which permits unrestricted, non-commercial use, distribution and reproduction in any medium, provided the work is properly cited. 